\title{
Assessment Of Practice Of Breast Self-Examination And Associated Factors Among Health Science Female Students Of Ambo University: Cross Sectional Study
}

Yohannes Bacha Gemechu ( $\nabla$ yohannesbacha@yahoo.com )

Ambo University https://orcid.org/0000-0002-9892-9269

Jatani Mitiku Gochole

Ambo University Referral

\section{Research}

Keywords: Breast, Feeding, Lactation, Practice, Factors

Posted Date: January 25th, 2021

DOI: https://doi.org/10.21203/rs.3.rs-151173/v1

License: (c) (1) This work is licensed under a Creative Commons Attribution 4.0 International License. Read Full License 


\section{Abstract}

Background: Breast Self-Examination is process whereby women examine their breasts regularly to detect any abnormal swelling or lumps in order to seek prompt medical attention. Breast cancer is the most prevalent cancer among women globally and the second commonest cancer overall. The aim of this study was to assess practice of breast self-examination and associated factors among Health science female students at Ambo University in 2019.

Methodology: - Institutional based cross-sectional survey was carried out among Health science female students at Ambo University in 2019. Data was collected by using a pre tested and pretested selfadministered questionnaires. The response was systematically tabulated and analyzed using SPSS version 20 , and explanations were given separately.

Result- A total of 150 respondents participated in the study, of these $80(53.3 \%)$ of them had good knowledge and only $67(44.7 \%)$ of the respondents had practiced BSE before. Among study participants whose families had breast cancer, practice BSE 2.12 times more than study participants whose families didn't have his tory of breast cancer (AOR=2.12;95\% $\mathrm{Cl}, 1.09-3.95, \mathrm{P}=0.044)$. Those who had good knowledge toward BSE were 5.5 times more likely to practice BSE than those who had poor knowledge (AOR=9.5; 95\% Cl, 5.5-18.8, $\mathrm{P}=0.002$ ).

Conclusions- The overall knowledge of female students towards breast self-examination was $62 \%$. This study showed that only $67(44.7 \%)$ of the study participants ever practiced BSE. The independeent predictors of breast self examination was family history of breast cancer and knowledge how to perform breast self examination.

\section{Background}

Breast cancer is one of the most commonly diagnosed cancer globally which accounts for 1.7 million cases in 2012 and there were 6.3 million women diagnosed with breast cancer in the previous five years (1).

The breast cancer continues to be a prominent women's health problem, representing $28 \%$ of all female cancer. The most common initial evidence of breast cancer is a lump. It is not known why cancerous tumors develop. At first, they remained confined in the breast, when they have grown a certain amount, they may spread to other parts of the body, this depends on the type of cell forming the tumor. The condition affects both breast only in $10 \%$ cased. $(2,3)$

Breast Self-Examination (BSE) is process whereby women examine their breasts regularly to detect any abnormal swelling or lumps in order to seek prompt medical attention. (4)

As many studies indicated the practices of BSE are low among university students. Limited knowledge about the realities of breast cancer and lack of knowledge about the importance of self-examination and 
how it is performed are the main barriers for not practicing BSE. $(4,5)$

The growth and aging of the population of the countries of low or middle income countries, together with Westernization of life style and the rapid growth of tobacco smoking, change in life style habits (more sedentary lifestyle, weight gain and obesity) and societal changes (increasing age at first birth and decreasing parity in women) are leading to large increases in breast and colorectal cancer (6).

In the United States, an estimated 246,660 new cases of invasive breast cancer are expected to be diagnosed in women in 2016, and about 40,450 of these women are expected to die (7). In Africa, breast cancer was also the most commonly diagnosed cancer and the second leading cause of death among women in 2008, 92,600 cases and 50,000 deaths were reported that year. Cancer are growing burden, and continues to receive relatively low public health priority in Africa, because of limited resource and more attention given to communicable disease $(8,9)$.

In Ethiopia, currently about 60,000 new cases of cancer is diagnosed each year and each day around ten to fifteen new patient seen (10).

The study conducted by Addis Ababa city cancer registry from 2011 to 2014, breast cancer is the leading type among females and accounts for $33 \%$ of all cases of cancer followed by cervix uteri which accounts for $17 \%(11)$.

The study done among female health science students at Adama science and Technology University showed knowledge and practice of breast self-examination was low. Only $8(5.5 \%)$ of the respondents practiced breast self-examination and $8.7 \%$ of the respondent had good knowledge (14). According to studies carried out in Ethiopia, there are several factors often cited by study participants as reasons for them not performing BSE. The prominent ones constitute lack of adequate awareness about the disease, not knowing the techniques, not seeing problems such as lumps on their breasts and having little or no information about BSE and its importance $(12,13,14)$.

Therefore, this study attempted to assess the BSE practice and associated factors among 1 st year health science female students in Ambo University, West shoa zone, Ethiopia, oromia region, 2019

\section{Methodology}

The study was conducted in Ambo University among 1st year health science female students by using institutional based cross-sectional study design. The study was conducted from October 15-February 13, 2019 GC

The sample size was determined using single population proportion formula with the assumption of marginal error of $5 \%, 5 \%$ of non-response rate, $95 \%$ confidence level and the prevalence of the breast selfexamination practice to be $28.3 \%$ from the study conducted in Debre Behran University[15]. 
Since the sample was drawn from a finite population, the correction formula was applied. Finally, the sample size of 165 was determined. The calculated sample size was proportionally allocated to each Department based on the number of female students in the college.

After proportionally assigning sample size to each department, a simple random sampling technique was applied to select study participants.

All-female students who were actively on education during data collection at each department were included.

Data was collected using pre-tested self- administered questionnaire. Te questionnaire was developed in the English language after reviewing and extracting from different pieces of literature developed for the same purpose. The knowledge of breast self-examination was assessed by multiple questions. Each correct answer was given as score of 1 and a wrong response a score of 0 .

According to bloom's classification cut off points for knowledge score

\section{Good knowledge}

a score of $80-100 \%$ of correct responses for knowledge questions

\section{Satisfactory knowledge}

a score of $60-79 \%$ of correct responses for knowledge questions

\section{Poor knowledge}

a score less than $60 \%$ of correct responses for knowledge questions.

Good practice of breast self-examination was who performed breast self-examination practice a week after each menses by their palm and middle three fingers otherwise called poor practice.

The collected data was cleaned, cheeked for completeness, compiled and data analysis were systematically tabulated and analyzed using statistical package for social sciences (SPSS) version 20 software. Descriptive statistics was used to see frequency, and percentage. Presentation of data was done by using tables and figures. To assess the association between dependent and independent variables by controlling for confounders, first binary logistic regression was run and variables with Pvalue $\leq 0.05$ and the variables which are known

to have an association with dependent variables from reviewed literature were selected for multiple logistic regression analysis. Statistical significance was declared at P-value $<0.05$ with $95 \%$ confidence interval $(\mathrm{Cl})$.

To ensure the data quality of our study the following measures were taken: 
The questionnaire was developed by reviewing relevant pieces of literature on the subject. Also, the questionnaire was pre-tested and modified where necessary. One day training was given for data collectors and supervisors.

Dependent variable: Breast self-examination practice (BSE).

During the fieldwork, the objective of the study was clearly explained for the study participants, the confidentiality of the data to be collected and the right not to participate also assured. Before starting the data collection process, written consent was taken from each respondent after they read and signed the consent form.

\section{Results}

\section{Socio Demographic Characteristics Of The Study Participants}

A total of 150 female students were responded to the distributed questionnaires, making a response rate of $91 \%$. The participants ranged from ages of 20 to 27 years old. As it can be seen from the table, Majority of the respondents (53.3\%) were protestants, $29.3 \%$ were orthodox, $16 \%$ were Muslim and there is $1.3 \%$ of waaqeffannaa religion followers (Table 1 ). 
Table 1

socio demographic characteristics of female students of Ambo University Health sciences students, Oromia region, Western Ethiopia, 2019

\begin{tabular}{|c|c|c|c|}
\hline \multicolumn{2}{|l|}{ Variables } & \multirow{2}{*}{$\begin{array}{l}\text { Frequency } \\
113\end{array}$} & \multirow{2}{*}{$\begin{array}{l}\% \\
75.3 \%\end{array}$} \\
\hline Age & $20-25$ & & \\
\hline & $26-30$ & 37 & $24.7 \%$ \\
\hline \multirow[t]{4}{*}{ Religion } & Orthodox & 44 & $29.3 \%$ \\
\hline & Muslim & 24 & $16 \%$ \\
\hline & Protestant & 80 & $53.3 \%$ \\
\hline & Other & 2 & $1.3 \%$ \\
\hline \multirow[t]{4}{*}{ Ethnicity } & Oromo & 87 & $58 \%$ \\
\hline & Amhara & 47 & $31.3 \%$ \\
\hline & Tigre & 7 & $4.7 \%$ \\
\hline & Others & 9 & $6 \%$ \\
\hline \multirow[t]{3}{*}{ Year of study } & $1 \mathrm{st}$ & 63 & $42 \%$ \\
\hline & 2nd & 48 & $32 \%$ \\
\hline & $3 r d$ & 39 & $26 \%$ \\
\hline \multirow[t]{5}{*}{ Department } & Nurse & 50 & $33.3 \%$ \\
\hline & Midwifery & 26 & $17.3 \%$ \\
\hline & Public health & 42 & $28 \%$ \\
\hline & Pharmacy & 20 & $13.3 \%$ \\
\hline & Medical laboratory & 12 & $8 \%$ \\
\hline
\end{tabular}

From the study participants, the majority of them (58\%) were Oromo, $31 \%$ were Amhara, and there is only $6.7 \%$ of the study participants were Tigre.

Their educational status was at the same level that all study participants was 1 st year health science students of different department. From the total participants, majority, $40 \%$ of them were from nursing department, $20 \%$ of the were from midwifery department, $16 \%$ of them were from pharmacy, and only $2.7 \%$ of the study participants were from medical laboratory departments

\section{Knowledge About BSE}


Majority, $93(62 \%)$ of the participants had good knowledge, and $57(38.8 \%)$ of the study participants had poor knowledge of breast self-examination (Fig. 1). From total participants, 112(74.7\%) was heard about BSE and 38(25.3\%) of the respondents have no any information about BSE. The main source of information of the breast self-examination was from class room teaching (64.5\%).

\section{Practice of study participants toward BSE}

This study showed that only $67(44.7 \%)$ of the study participants ever practiced BSE, including 38 (56.7\%) participants who performed BSE every month, $17(25.4 \%)$ participants who performed once in a week and $12(17.9 \%)$ participants who performed once in a year (Fig. 2).

The study respondents who practice BSE, majority, 30 (44.8\%) of the respondents uses circular technique during BSE, 19 (28.4\%) of them use wedge technique, $11(16.4 \%)$ of them uses vertical technique, and 7 $(10.4 \%)$ of the study respondents uses all the above technique.

The majority of the participants, $83(55.3 \%)$ who did not perform BSE, were further asked on their reasons for not performing BSE, and 21 (25.3\%) said that they lack of knowledge, 19(22.9\%) followed by negligence, and $18(21.7 \%)$ fear of detecting something abnormal $15(18 \%)$ of them said carelessness, and10 (12\%) of them said forgetfulness (Fig. 3).

Regarding the questions about their family history 35(23.4\%) of the participants have family history (mother or sister) breast cancer and were $115(76.6 \%$ ) did not had family history of breast cancer, from the participant who had family history of BC $15(42.9 \%)$ were responds know that at risk for developing breast cancer and $57.1 \%$ should not know that at risk for developing breast cancer.

\section{Factors Associated With Practice Of Breast Self-examination}

To see the effect of independent variables on dependent variable (practice of BSE), bivariate and multivariate logistic regression analyses were carried out. The analysis was done by including sociodemographic characteristics, history of breast cancer, and knowledge of BSE.

A result obtained from bivariate and multivariate logistic regression showed that family history of breast cancer, and knowledge have a signifcant association with practice of BSE. Among study participants whose families had breast cancer, practice BSE 2.12 times more than study participants whose families didn't have his tory of breast cancer $(A O R=2.12 ; 95 \% \mathrm{Cl}, 1.09-3.95, \mathrm{P}=0.044)$.

Those who had good knowledge toward BSE were 5.5 times more likely to practice BSE than those who had poor knowledge (AOR $=9.5 ; 95 \% \mathrm{Cl}, 5.5-18.8, \mathrm{P}=0.002)($ Table 2$)$. 
Table 2

Factors associated with BSE practice among female undergraduate students of health science in Ambo University, College of Medicine and Health science, Ambo, Ethiopia, 2019

\begin{tabular}{|c|c|c|c|c|c|c|c|}
\hline \multicolumn{2}{|l|}{ Variables } & \multicolumn{2}{|c|}{ BSE practice } & \multirow{3}{*}{$\begin{array}{l}\mathrm{COR}(95 \% \\
\mathrm{Cl})\end{array}$} & \multirow{3}{*}{$\begin{array}{l}\mathrm{P}- \\
\text { value }\end{array}$} & \multirow{3}{*}{$\begin{array}{l}\text { AOR }(95 \% \\
\mathrm{Cl})\end{array}$} & \multirow{3}{*}{$\begin{array}{l}\mathrm{P}- \\
\text { value }\end{array}$} \\
\hline & & \multirow{2}{*}{$\begin{array}{l}\text { Yes } \\
\mathrm{N}(\%)\end{array}$} & \multirow{2}{*}{$\begin{array}{l}\text { No } \\
\mathrm{N}(\%)\end{array}$} & & & & \\
\hline & & & & & & & \\
\hline \multirow[t]{3}{*}{$\begin{array}{l}\text { Family history of } \\
\text { breast cancer }\end{array}$} & Yes & $27(77)$ & $8(23)$ & $\begin{array}{l}3.32(1.11- \\
3.24)\end{array}$ & 0.039 & 2.12 & $0.044^{*}$ \\
\hline & No & $40(34.8)$ & $75(65.2)$ & 1.00 & & & \\
\hline & & & & & & 1.00 & \\
\hline \multirow{2}{*}{$\begin{array}{l}\text { Personal history of } \\
\text { breast cancer }\end{array}$} & Yes & $7(46.7)$ & $8(53.3)$ & $4.52(5.09-$ & 0.008 & $2.02(3.07-$ & $0.004^{\star}$ \\
\hline & No & $60(44.4)$ & $75(55.6)$ & 1.00 & & 1.00 & \\
\hline \multirow[t]{2}{*}{ Ever heard of BSE } & Yes & $53(47.3)$ & $59(52.7)$ & $\begin{array}{l}1.87(1.09- \\
3.7)\end{array}$ & 0.049 & $\begin{array}{l}1.01(1.01- \\
3.04)\end{array}$ & $0.040 *$ \\
\hline & No & 14(36.8) & $24(63.2)$ & 1.00 & & 1.00 & \\
\hline \multirow{2}{*}{$\begin{array}{l}\text { Knowledge toward } \\
\text { BSE }\end{array}$} & Poor & $9(15.8)$ & $48(84.2)$ & 1.00 & 0.003 & 1.00 & $0.002^{*}$ \\
\hline & Good & $58(62.4)$ & $35(37.6)$ & $\begin{array}{l}10.73(9.64- \\
18.8)\end{array}$ & & $\begin{array}{l}9.5(7.09- \\
18.8)\end{array}$ & \\
\hline \multicolumn{8}{|c|}{ COR crudes odds ratio, AOR adjusted odds ratio } \\
\hline \multicolumn{8}{|c|}{ *significantly associated } \\
\hline
\end{tabular}

\section{Discussions}

Among the study participants $62 \%$ of them had good knowledge of breast self-examination. A crosssectional study done among female medical students in Adama health science and technology university, Ethiopia, showed that only (8.7\%) of the study respondents had good knowledge. This significant difference may be attributed to the difference in the number of participants that in this study, and exposure to theoretical learning.

Also, the finding of the study among Female University students in Presbyterian University College, Ghana showed that $95 \%$ of the respondents had good knowledge about BSE which was higher compared to this study. This might be explained by the fact that the study participants were senior female nursing students who had better clinical knowledge about BSE and who don't have good clinical knowledge when compared to the above study in Ghana which is done among senior health science female students. 
According to this study, $74.7 \%$ of the study participants had heard about breast self-examination previously. In this study the major source of information about BSE was class room teaching which accounted for $64.5 \%$. The case was different in other studies conducted in Ghana (48\%) and Mekele, Ethiopia, $58.5 \%(32,33)$ where major source of information about breast self-examination was mass media(TV, Radio, Magazine and Newspaper).

In this study, $44.4 \%$ of the study participants have practiced breast self-examination. The study done in Adama health Science and Technology University showed almost similar practice of BSE at $39.4 \%$ and there is a little, bit difference with this study. Compared to this study, the finding of the study done in Mekele city indicated that higher percentage of participants $53.6 \%$ practiced BSE.

In this study the main reasons for not practicing BSE as explained by participants were not knowing how to perform breast self-examination, negligence, fear of detecting abnormality in their breast, carelessness and forgetfulness. Similarly, in the study carried out in Buena, Cameron the number one reason for not performing BSE was having no sign of breast cancer.

Another studies conducted in Mekele, Gojam, Ethiopia also showed that the main reasons for not performing breast self-examination were having no breast problem, not knowing breast self-examination technique, not knowing the importance of breast self-examination and absence of breast symptoms or disease.

\section{Conclusions}

The overall knowledge of female students towards breast self-examination was $62 \%$. This study showed that only $67(44.7 \%)$ of the study participants ever practiced BSE, including 38 (56.7\%) participants who performed BSE every month, 17(25.4\%) participants who performed once in a week and $12(17.9 \%)$ participants who performed once in a year.

The independeent predictors of BSE was family history of breast cancer and knowledge how to perform breast self-examination.

Finally, additional community based research should be needed for the future to improve understanding of the community on practice of breast self- examination.

\section{Abbreviations}

AU: Ambo University; BC: Breast Cancer; BSE: Breast Self-Examination; CA: Cancer: CBE: Clinical Breast Examination; FAN: Fine Needle Aspiration; OPC: Out Patient Clinic; USA: United States of America; SPSS: statistical package of social science; WHO: World Health organization.

\section{Declarations}




\section{Ethics approval and consent to participate}

The proposal for the study was submitted to Department of Nursing of College of Medicine and Health Sciences, Ambo University for approval and clearance. Accordingly, the study was checked for its ethical issue and permission letter was obtained. The letter for support was written from Department of Nursing to all concerned student's department. Before starting the data collection process, oral consent was taken from each respondent after they read and signed the consent form.

Consent for publication: Not applicable

Availability of data and materials: Not applicable

\section{Competing interests}

The authors declare that they have no competing interests.

\section{Funding}

The Research was not funded by any organization and also the organization has no role in designing the study, data collection, or manuscript preparation.

\section{Authors' contributions}

All authors participated in data collection, analysis, interpretation and approved the final manuscript. Yohannes Bacha is the guarantor of the paper.

\section{Acknowledgements}

We would like to thank Ambo University Nursing Department for giving this chance to conduct this research. Also, we would like to thank data collectors and study participants.

\section{References}

1. Lemlem SB, Sinishaw W, Hailu M, Abebe M, Aregay A. Assessment of knowledge of breast cancer and screening methods among nurses in University Hospitals in Addis Ababa, Ethiopia, 2011. ISRN Oncol. 2013;2013:470981

2. International Agency for Research on Cancer (IARC), Latest world cancer statistics, 2013

3. Breast cancer A guide for journalists on breast cancer and its treatment.

4. H. Forouzanfar, K. J. Foreman, A.M. Delos Santos et al., "Breast and cervical cancer in 187 countries between 1980 and 2010," The Lancet, vol. 378, no. 9801, pp. 1461-1484, 2011.View at Publisher . View at Google Scholar · View at Scopus

5. Chong PN, Krishnan M. Hongcy, SwahTs. Knowledge and practice of breast cancer screening amongst public health nurses in Singapore, Singapore med, (2002); 43:509-16 
6. WHO (IARC) World Cancer Report 2008

7. Breast cancer.Org. S. Breast Cancer Statistics. U.S. Breast Cancer Statistics_Breastcancer.org.htm/ (accessed 16 October 2016).

8. Breastcancer.preventionandcontrol. http://www.who.int/cancer/detection/breastcancer/en/ (accessed 17 October 2016).

9. Jamal A, DVM, PhD1; Bray F, PhD2; Forman D, PhD2; Brien M, PhD3; Ferlay J, BS2; Melissa Center, MPH1; and Parkin M.D, MD4,5. Cancer Burden in Africa and Opportunities for Prevention. Wiley Online Library (wileyonlinelibrary.com) 17 January 2012; 118(18): 4372-4384.

10. World health organization. Cancer - a Growing Public Health Concern for Ethiopia. http://www.afro.who.int/en/ethiopia/press-materials/item/7062-cancer-a-growing-public-healthconcern-for-ethiopia.html (accessed14November2016).

11. AddisAbabaCity Cancer Registry. http://afcrn.org/membership/members/100-Addisababa (accessed 29 October 2016).

12. Azage M., Abeje G., and Mekonnen M. Assessment of Factors Associated with Breast SelfExamination among Health Extension Workers in West Gojjam Zone, Northwest Ethiopia. International Journal of Breast Cancer 2013;

13. Hailu T., Berhe H., Hailu D, *, Berhe H. Knowledge of breast cancer and its early detection measures among female students, in Mekelle University, Tigray region, Ethiopia. Science Journal of Clinical Medicine 2014; 3((4):): 57-64.

14. Segni T.M*, Tadesse M.D, Amdemichae.R , and Demissie F.H. Breast Self-examination: Knowledge, Attitude, and Practice among Female Health Science Students at Adama Science and Technology University, Ethiopia. Gynecology Obstetrics 2016;6(4):

15. Kalayu B, Misikir A; Belayneh A, Gebru G, Ruth D, etal. Practices of Breast Self-Examination and Associated Factors among Female Debre Berhan University Students, Debre Berhan, Ethiopia. International Journal of Breast Cancer. 2017.

\section{Figures}




\section{Knowledge of female students towards BSE}

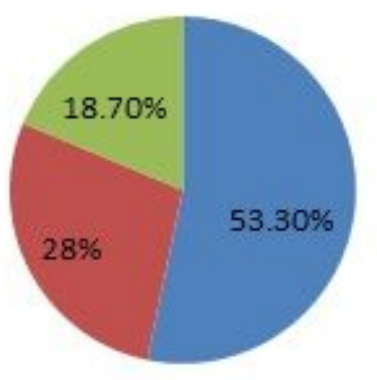

- Good knowledge

natisfactory knowledge

- Poor knowledge

\section{Figure 1}

Knowledge towards breast self-examination among female students of Ambo University Health sciences students, Oromia region, Western Ethiopia, 2019

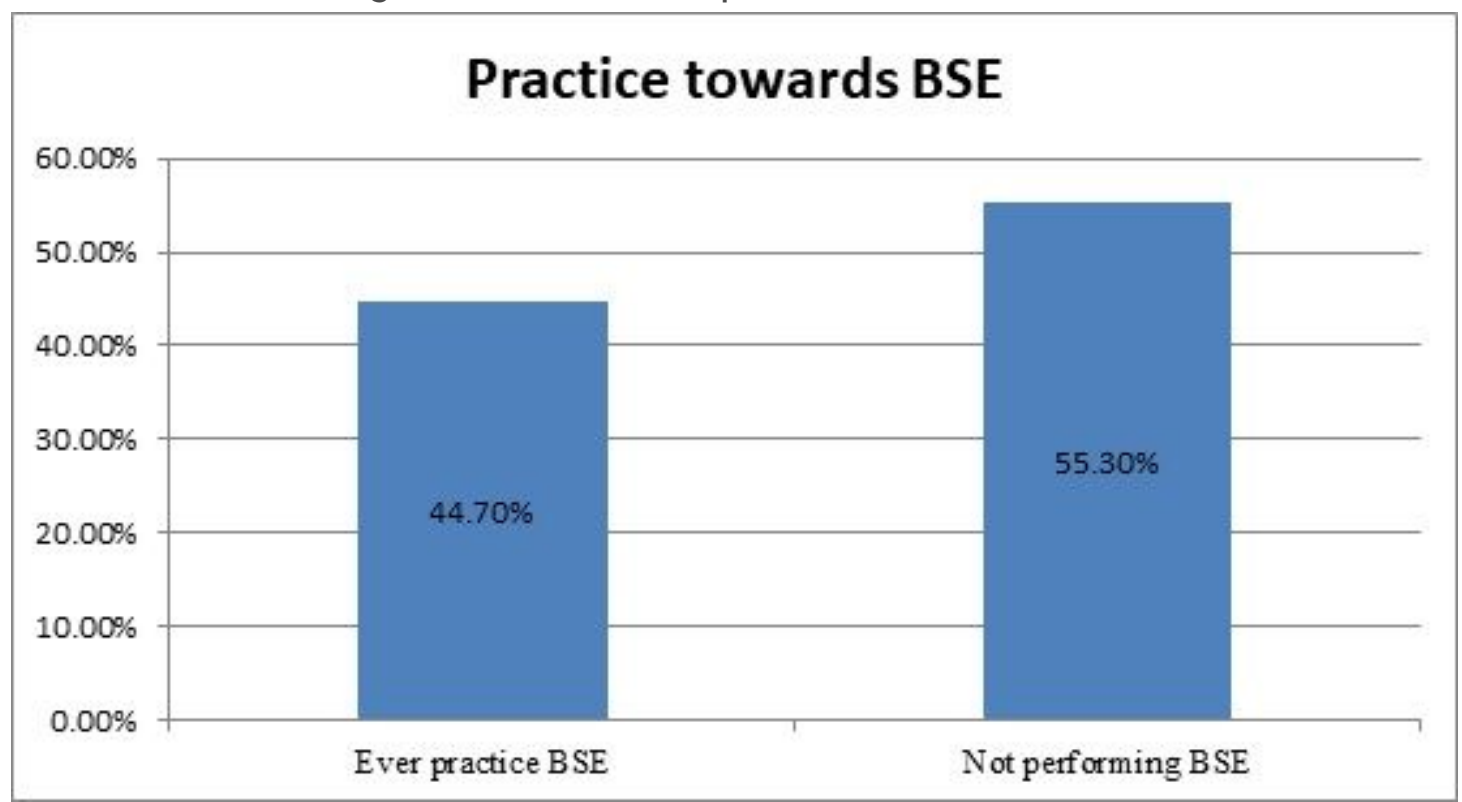

\section{Figure 2}

Practice towards breast self-examination among female students of Ambo University Health sciences students, Oromia region, Western Ethiopia, 2019 


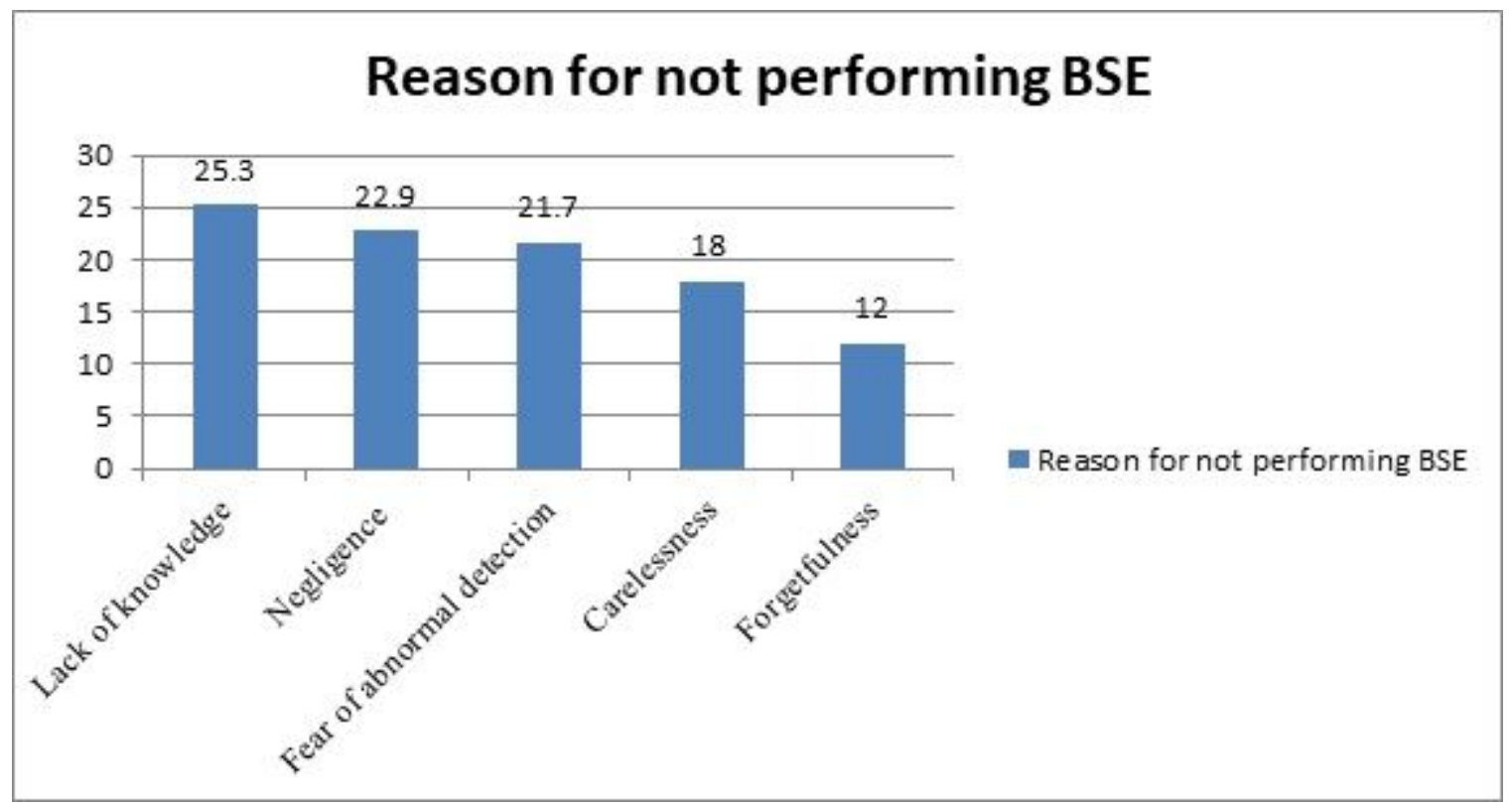

\section{Figure 3}

Reason for not performing breast self-examination among female students of Ambo University Health sciences students, Oromia region, Western Ethiopia, 2019 